\title{
Orchestration Signals in the Classroom: Managing the Jigsaw Collaborative Learning Flow
}

\author{
Davinia Hernández-Leo, Raul Nieves, Ernesto Arroyo, \\ Andrea Rosales, Javier Melero, Pau Moreno, Josep Blat \\ GTI, ICT Department, Universitat Pompeu Fabra, Roc Boronat 138, \\ 08018 Barcelona, Spain \\ \{davinia.hernandez, raul.nieves, ernesto.arroyo, \\ andrea.rosales, javier.melero, pau.moreno,josep.blat\}@upf.edu
}

\begin{abstract}
The orchestration of collaborative learning processes in face-to-face physical settings, such as classrooms, requires teachers to coordinate students indicating them who belong to each group, which collaboration areas are assigned to each group, and how they should distribute the resources or roles within the group. In this paper we present an Orchestration Signal system, composed of wearable Personal Signal devices and an Orchestration Signal manager. Teachers can configure color signals in the manager so that they are transmitted to the wearable devices to indicate different orchestration aspects. In particular, the paper describes how the system has been used to carry out a Jigsaw collaborative learning flow in a classroom where students received signals indicating which documents they should read, in which group they were and in which area of the classroom they were expected to collaborate. The evaluation results show that the proposed system facilitates a dynamic, visual and flexible orchestration.
\end{abstract}

Keywords: computer-supported collaborative learning, orchestration, ubiquitous wearable devices, flexible learning flow

\section{Introduction}

Physical spaces, such as classrooms or the playground, have a relevant role in collaborative learning since they can bring students together and shape their interactions [1, 2]. The characteristics of a particular space can encourage experimentation, exploration, collaboration, and discussion. The introduction of technologies in physical educational spaces has brought new possibilities that are transforming the learning experiences [3]. Computational artifacts such as media representation systems, remote interaction systems, room-scale peripherals and devices such as handhelds have moved from being conceived as means to support distance communication and learning to be elements embedded in augmented physical spaces that can enrich face-to-face learning experiences $[4,5]$. Teachers can design new learning strategies according to their perceived affordance regarding the properties of these technologies [6]. 
Technology-enhanced educational spaces go beyond the desktop computing by using interactive artifacts and computing facilities derived from three fields: tangible user interfaces, ubiquitous computing and augmented reality [7]. Tangible user interfaces involve explicit contact with the computing artifacts such as tabletops, smartboards, multitouch screens and tangible building blocks [8, 9, 10, 11]. Ubiquitous computing deals with situating and embedding devices within a space so that computational power is available everywhere and the interaction with the devices is mediated through this space. This is now possible due to improvements in computing power, hardware size, wireless communications, power management, and software architectures. Ubiquitous computing offers new possibilities for helping people organize and work collaboratively, mediating social interactions in technology-rich spaces. Ubiquitous computing devices used to support learning settings include light-weight and roomware awareness tool devices [12], mobile phones, QR codes, radio-frequency identification tags and GPS [13, 14, 15]. The devices can incorporate sensors, actuators or both, and can also be network linked. These tangible and ubiquitous devices are augmenting the reality, in the sense that they overlay and add digital information to real objects or integrate computer power into them $[5,16]$.

In this paper, we introduce a system that adds digital orchestration information to ubiquitous devices that can be worn by students. This orchestration information refers to coordination aspects of collaborative learning processes [17], such as group formation indicators, signals to indicate the distribution of resources during the activity, etc. While the orchestration problem has been to a large extent solved in the context of PC-oriented learning environments (see for example the collaborative learning flows created with Collage and run in IMS LD compliant systems [18]), no solutions have been proposed to provide coordination information to students in wearable devices so that the use of a PC is not required and, therefore, more agile dynamics in different spaces are enabled. We have considered low-cost wearable devices in contrast to mobile phone-based approach because, on the one hand, phones tend to be more expensive, sometimes it is difficult for a teacher to ensure that every student will own one which is compliant with the system requirements, and students can lose the concentration on the activity if they play with other mobile applications. On the contrary, wearable devices could be designed so that they are more visual and generic and can be used by students at any educational level in the classroom, the playground, etc.

The system, named Orchestration Signal system, has been used and evaluated in a real learning situation where 27 students are expected to follow a Jigsaw collaborative learning flow [19] for the collaborative analysis of three cases. According to the Jigsaw pattern, in a first phase students read individually one of the cases, in the second phase they meet in expert groups with other students that have read the same cases, and finally, in the third phase, the students join Jigsaw groups composed of students that have read different cases so as to solve a common problem that required the knowledge studied in the three cases. The research questions explored in the evaluation are: Does the orchestration signals enable/facilitate the coordination of the Jigsaw learning flow in the classroom? Are the orchestration signals flexible enough to deal with unexpected situations? Are the characteristics of the prototype usable for 
the purposes of the Jigsaw learning flow orchestration? What aspects need/can be improved?

The remainder of the paper is structured as follows. Section 2 describes the design, functioning and modules of the Orchestration Signal system. Then, section 3 explains the activity and educational context where the system has been used for its evaluation. The evaluation results are presented in section 4. Finally, section 5 is devoted to conclude the paper and indicate the future lines of research derived from this research work.

\section{The Orchestration Signal system prototype}

The Orchestration Signal system prototype includes multiple Personal Signal devices (PS-device), which have visualization module and a communication module, and the Orchestration Signal manager (OS-manager), a graphical user interface to monitor and control the experience. As illustrated in Fig. 2, the PS-device visualization module displays several color combinations associated to signals that teachers would like to send students for indicating orchestration aspects of the collaborative learning flow, such as resources distribution or group formation. It consists of 4 leds (red, green, blue and yellow), which can be turned on and off individually or in pairs trough a communication module. This module includes a transceiver RF12B that allows the PS-device to be remotely controlled by a central computer from up to 100 meters away. A central computer (e.g., the PC in the classroom or the teachers' laptop) runs the OS-manager where teachers can configure the orchestration signals to be transmitted to the PS-devices.

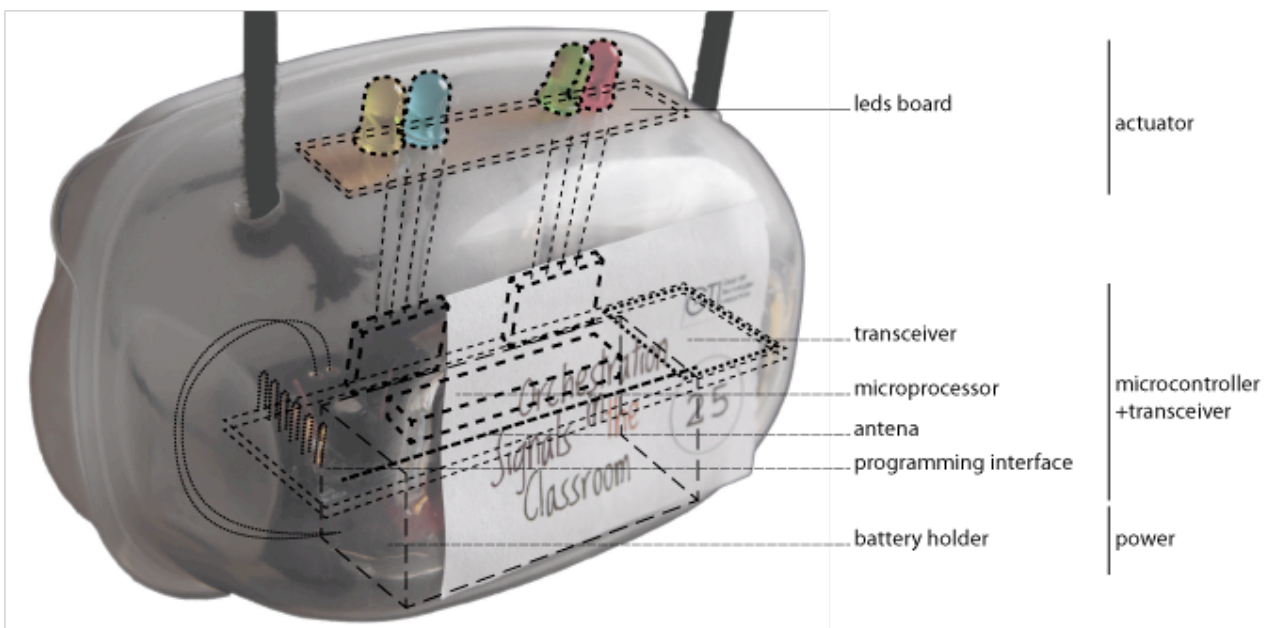

Fig. 1. Personal Signal device (PS-device) 
The hardware used in the development of the PS-devices is based on JeeNodes, a low-cost Arduino clone board [20]. The board is powered by 3 AA batteries and includes an ATmega328 microcontroller which supports embedding programmed logic.

The system includes a master node that relays commands between the computer with the OS-manager and each PS-device. The communication is unidirectional in order to avoid message sequencing and bottlenecks. Moreover, the data sent is coded into only 1 byte in order to optimize communication speed data transfer rate.

The central computer hosts the OS-manager with a uni-directional serial link with the master node. The OS-manager interface visualizes a canvas box associated to each PS-device (see Fig. 2). In each canvas teachers can configure two possible types of signals (a color or a combination of two colors) to be sent to each device. Besides the OS-manager has three buttons for controlling batch message transfer. Two of the buttons send either the first or second color combination that each PS-device is setup to. The third button turns all units off.

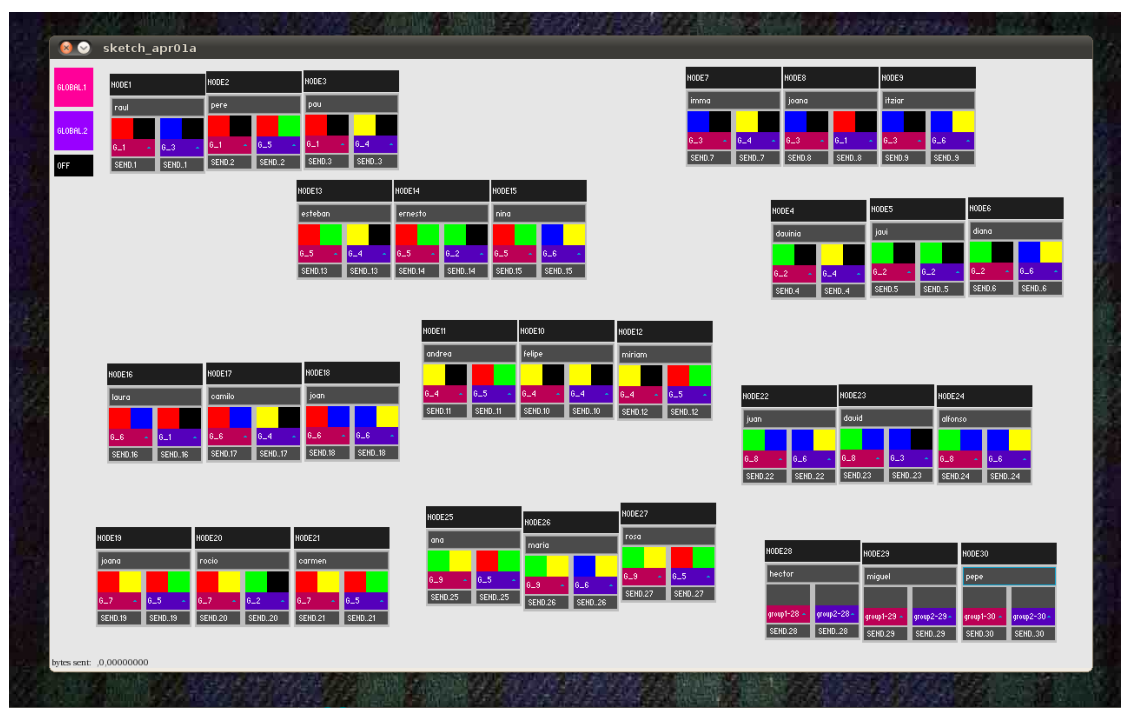

Fig. 2. Orchestration-Signal manager (OS-manager)

A unique number that matches the internal configuration and external labeling of each device identifies each PS-device in the OS-manager. The graphical box representing each device in the OS-manager also holds an input text-field to be filled with the name of the student for quicker identification. Bellow each box, a small button allows for individual signal transfer, in order to enable testing, individual correction, and group-membership readjustment. Each box can be freely dragged and dropped within the canvas, so that teachers can order them for a comfortable use (for example, arranging them to emulate the physical classroom arrangement).

The physical casing of the PS-devices was selected to be physically and visually unobtrusive so as to minimally disrupt the user's activity. The devices can be moved and rotated freely around the participants' neck to allow for a better viewing angle, or to share and match their visual indicator to that of their partners. The visual signal 
indicator is also located on a surface oriented to optimally display the illuminated led lights when seen from above. Finally, the casing is low-cost for a prototype and can be easily replaced.

\section{Activity based on the Jigsaw collaborative learning flow}

The activity proposed for testing the Orchestration Signal system prototype is framed in the context of a master seminar on Education \& Media Communication. A total of 27 students, with 12 different nationalities -6 men and 21 women, were enrolled in the seminar. Most of them (20) had a media communication or journalism background, 3 are pedagogues, and the remainder had a diverse background. All of them are interested in the educational field, however their use of educational technologies is limited (for example, only 4 have used the Moodle platform, and 1 has used the Blackboard management system). Table 1 summarizes the design of the activity following the structure of the Jigsaw collaborative learning flow pattern.

Table 1. Design of the activity according to the Jigsaw collaborative learning flow

\begin{tabular}{|c|c|c|}
\hline $\begin{array}{c}\text { Phases of the Jigsaw } \\
\text { Collaborative Learning } \\
\text { Flow Pattern [19] }\end{array}$ & $\begin{array}{l}\text { Specific activity in a scenario for the } \\
\text { collaborative reading of three cases on } \\
\text { the use of ICT in Education }\end{array}$ & $\begin{array}{l}\text { Distribution in the classroom } \\
\text { and signal required }\end{array}$ \\
\hline $\begin{array}{l}\text { Initial phase: Jigsaw } \\
\text { Groups are formed in } \\
\text { order to collaboratively } \\
\text { solve a global problem or } \\
\text { task. This problem is } \\
\text { divided into sub-problems. } \\
\text { Each student in a Jigsaw } \\
\text { Group studies a sub- } \\
\text { problem. }\end{array}$ & $\begin{array}{l}\text { Since there are three cases }(\mathrm{A}, \mathrm{B}, \mathrm{C}) \text {, the } \\
\text { Jigsaw groups need to be formed by a } \\
\text { minimum of three members (each of } \\
\text { them having read a different case). Since } \\
27 \text { students are enrolled in the course, it } \\
\text { is expected that } 9 \text { students will read each } \\
\text { case and, therefore, } 9 \text { Jigsaw groups will } \\
\text { be formed. } \\
\text { In this phase each student reads the } \\
\text { assigned case (A, B or C) and answers a } \\
\text { number of proposed questions about the } \\
\text { case. }\end{array}$ & $\begin{array}{l}\text { In this initial phase, since the } \\
\text { activity is individual, the } \\
\text { members of each Jigsaw group } \\
\text { do not need to be physically } \\
\text { close in the classroom, however } \\
\text { they should pick one case (out } \\
\text { of three) so that in each member } \\
\text { of a Jigsaw group reads a } \\
\text { different case. } \\
\text { Orchestration signal required: } \\
\text { indicating the case to pick }\end{array}$ \\
\hline $\begin{array}{l}\text { Expert phase: Students } \\
\text { having worked on the } \\
\text { same sub-problem meet, } \\
\text { forming Expert Groups, in } \\
\text { order to exchange ideas } \\
\text { about their sub-problem. }\end{array}$ & $\begin{array}{l}\text { In order to have Expert Groups of a } \\
\text { reasonable size, a total of } 6 \text { Expert } \\
\text { groups will be formed (there will be two } \\
\text { Expert Groups on the same case, each of } \\
\text { them with } 4 \text { or } 5 \text { students having read } \\
\text { the same case). The members of each } \\
\text { Expert group will meet in order to reflect } \\
\text { on the case and discuss their answers to } \\
\text { the questions. }\end{array}$ & $\begin{array}{l}\text { Expert groups will meet in a } \\
\text { specific work area of the } \\
\text { classroom so that they are close } \\
\text { to each other. These areas } \\
\text { should be as much separated as } \\
\text { possible from each other. } \\
\text { Orchestration signal required: } \\
\text { indicating expert groups and } \\
\text { group working areas }\end{array}$ \\
\hline $\begin{array}{l}\text { Jigsaw phase: Students of } \\
\text { each Jigsaw Group meet } \\
\text { again and each member } \\
\text { contributes with their } \\
\text { expertise in order to solve } \\
\text { the global problem. }\end{array}$ & $\begin{array}{l}\text { The three members of each Jigsaw group } \\
\text { will meet and compare the cases from } \\
\text { the perspective of the proposed } \\
\text { questions (which are common to the } \\
\text { cases). The group must complete an on- } \\
\text { line form with an agreed description of } \\
\text { the differences identified in the cases for } \\
\text { each question. }\end{array}$ & $\begin{array}{l}\text { Jigsaw groups will meet in a } \\
\text { specific work area of the } \\
\text { classroom so that they share a } \\
\text { PC and are close to each other. } \\
\text { These work areas should be as } \\
\text { much separated as possible from } \\
\text { other Jigsaw groups. } \\
\text { Orchestration signal required: } \\
\text { indicating Jigsaw groups and } \\
\text { group working areas }\end{array}$ \\
\hline
\end{tabular}


The activity consisted in the collaborative reading of three cases explaining different real scenarios that apply ICT to enhance learning. The cases included a narrative describing the scenarios and a set of questions that students had to answer. Table 2 also specifies the expected number of groups and members as well as the requirements regarding the distribution of resources and spaces in the classroom and, in consequence, the signals needed in order to indicate students the orchestration aspects of the activity.

The signals associated to individuals (students) were distributed using the Orchestration Signal system. However, the signals needed to identify the cases and the group working areas or spaces were built using color cardboards, so that they matched the LED colors, such as those in Fig. 3.

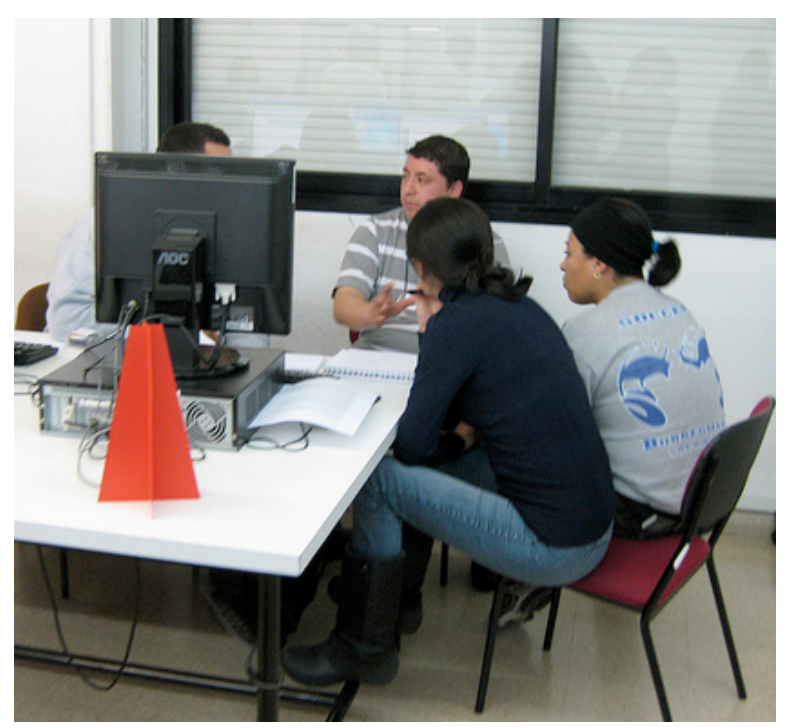

Fig. 3. Color cardboards to signal the collaboration working areas

\section{Evaluation}

To evaluate the research questions posed in the introduction regarding the facilitation of the orchestration and usability of the approach, we followed a mixed evaluation method [21] combining quantitative and qualitative data and the use of several data gathering techniques. These data are triangulated [22] in order to provide trustworthy results. The data gathering techniques were: observations collected by 2 researchers they noted down information regarding timing, incidents, use of devices, etc.; postquestionnaires with closed and open questions for students; and post-questionnaires with open questions for teachers. Two teachers of the seminar completed this questionnaire. They did not belong to the research team proposing the Orchestrating Signal system. 
Table 2 describes the actual enactment of the experience in comparison to the expected situation summarized in Table 1 . The table lists incidents of different nature that occurred in the different phases of the activity, the resulting composition of expert and Jigsaw groups and the time that was needed for accomplishing the orchestration aspects and performing the tasks. Fig. 4 shows some images illustrating the use of the PS-devices.

Table 2. Actual enactment of the experience (as annotated by the observers)

\begin{tabular}{|c|c|c|c|}
\hline Phases & Incidents & Actual enactment vs. what was planned & Actual timing \\
\hline $\begin{array}{l}\text { Initial } \\
\text { phase }\end{array}$ & $\begin{array}{l}\text { - } 3 \text { students } \\
\text { did not attend } \\
\text { the class } \\
\text { (total number } \\
\text { of students in } \\
\text { the class: } 24 \text { ) } \\
\text { - The red led } \\
\text { of PS-device } \\
\mathrm{n}^{\circ} 24 \text { did not } \\
\text { work }\end{array}$ & $\begin{array}{l}\text { - The distribution of cases in the S-manager had to } \\
\text { be changed so that each case was read by a } \\
\text { balanced number of } 8 \text { students (not } 9 \text { as expected). } \\
\text { The configuration of groups were also changed so } \\
\text { that expert groups were composed of } 4 \text { members, and } \\
\text { every Jigsaw group ( } 8 \text {, not } 9 \text { as expected) included } 3 \\
\text { members, each of them expert in a different case } \\
\text { - } 23 \text { students picked and read the correct case, pre- } \\
\text { assigned by the teacher in the S-manager, according } \\
\text { to the signals received in their PS-device } \\
\text { - } 1 \text { student picked and read an incorrect case (case } \\
\text { B), not the one pre-assigned by the teacher in the S- } \\
\text { manager (case A), since the student only saw the } \\
\text { green signal in the PS-device (not the green-red } \\
\text { signal as expected) } \\
\text { - Case A was read by only } 7 \text { students, case B was } \\
\text { read by } 9 \text { students, case C was read by } 8 \text { students }\end{array}$ & $\begin{array}{l}\text { Presenting the whole } \\
\text { activity: } 10 \text { minutes } \\
\text { Orchestration: } 1 \text { minute } \\
\text { (teacher sends signal and } \\
\text { students receive signals), } \\
2 \text { minutes (students pick } \\
\text { their cases marked with } \\
\text { colors - corresponding } \\
\text { to the signals), total of } 3 \\
\text { minutes } \\
\text { Task (reading the case): } \\
12 \text { minutes }\end{array}$ \\
\hline $\begin{array}{l}\text { Expert } \\
\text { phase }\end{array}$ & $\begin{array}{l}\text { - Student with } \\
\text { PS-device } \mathrm{n}^{\circ} \\
15 \text { had to } \\
\text { leave the } \\
\text { class during } \\
\text { the expert } \\
\text { phase }\end{array}$ & $\begin{array}{l}\text { - Because of the problem with PS-device } 24, \mathbf{1} \text { of the } \\
\text { expert groups was composed of } \mathbf{3} \text { members and } \\
\text { another expert group was composed of } \mathbf{5} \text { members } \\
\text { - The student with PS-device } 15 \text {, leaving the class, } \\
\text { was a member of the group with } 3 \text { members, } \\
\text { therefore this group finished with activity with only } \\
\mathbf{2} \text { members } \\
\text { - At the end of the expert phase, only } 6 \text { students were } \\
\text { expert in case A }\end{array}$ & $\begin{array}{l}\text { Orchestration (receiving } \\
\text { the signal and joining the } \\
\text { expert group in the area } \\
\text { of the classroom } \\
\text { indicated with a similar } \\
\text { signal): } 2 \text { minutes } \\
\text { Task (discussing the } \\
\text { case): } 15 \text { minutes }\end{array}$ \\
\hline $\begin{array}{l}\text { Jigsaw } \\
\text { phase }\end{array}$ & - No incidents & $\begin{array}{l}\text { - The Jigsaw groups composition was changed } \\
\text { again in the PS-manager so that all the groups had at } \\
\text { least one member expert in every case. A total of } 6 \\
\text { Jigsaw groups were defined, } 5 \text { of each composed of } \\
4 \text { members and } 1 \text { formed of } 3 \text { members. While } \\
\text { each had a member expert in case A, } 5 \text { of the groups } \\
\text { have } 2 \text { experts either in case B or C }\end{array}$ & $\begin{array}{l}\text { Orchestration (receiving } \\
\text { a new signal and joining } \\
\text { the expert group in the } \\
\text { area of the classroom } \\
\text { indicated with a similar } \\
\text { signal): } 1 \text { minute } \\
\text { Task (explaining cases, } \\
\text { completing on-line } \\
\text { form): } 20 \text { minutes }\end{array}$ \\
\hline
\end{tabular}



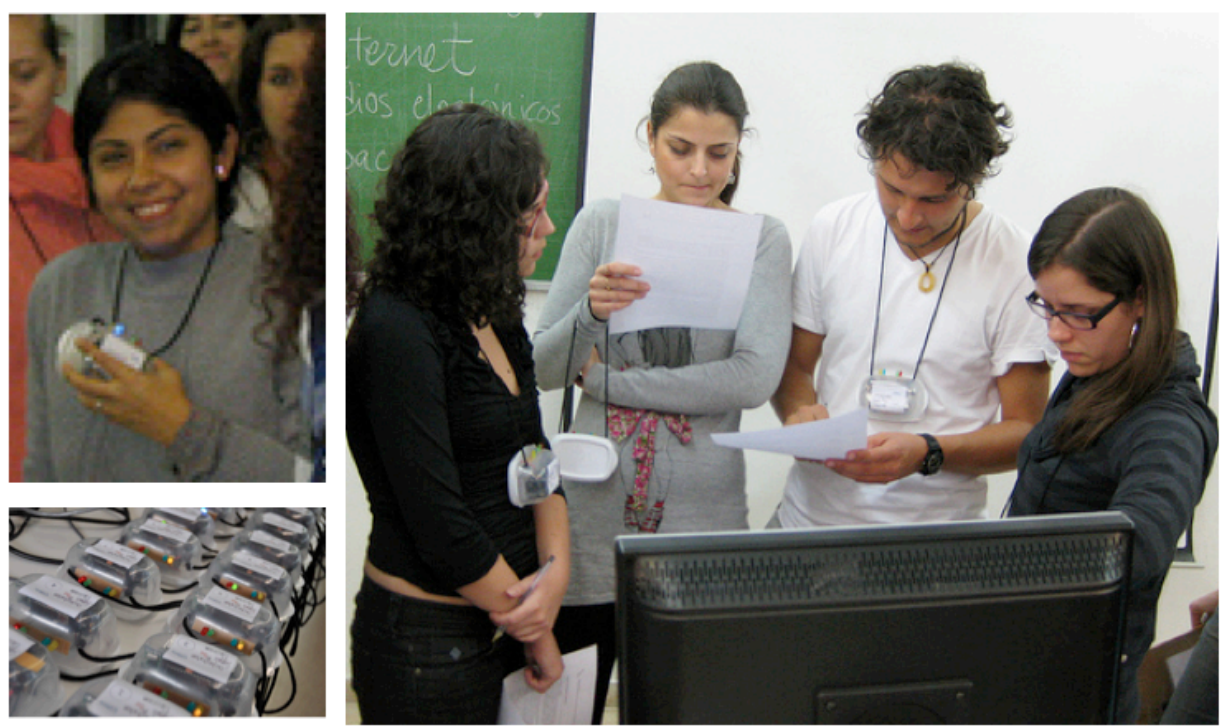

Fig. 4. Pictures taken during the experience

The analysis of the data shows that the experience was successful in the orchestration of the Jigsaw collaborative learning flow (see Table 3). The system enabled a distribution of signals to the personal devices worn by the students, so that students knew automatically, and without "social indications" by the teachers, which case they should read and to which group they belong. As a result, the teachers' orchestration workload decreased as compared to their previous experiences (S1-2, T1-2). Besides configuring the OS-manager, the orchestration tasks carried out by the teacher were limited to explaining the meaning of the signals, distributing the cardboard signals to identify collaboration areas in the classroom and noting when the phases finished (the colors of the cardboards matched with the group signals received in the PS-devices; S3, O12).

Most of the students found the approach useful (84\% rated it as quite or very useful). Those students not finding it useful indicated that the system was not indispensable to carry out the activity (S4-5-6). A critical element that led to the successfulness of the orchestration was the flexibility supported by the approach. Despite the unexpected incidents (O4-5) that occurred during the experience, teachers were able to re-configure the design of the orchestration transparently to the students (T3-4). Though it is true that the activity could have been carried out without the use of the system, the provided transparent flexibility and the decrease in the orchestration workload represent important added values of the approach. The relevance of these values is higher if we consider a higher number of students involved in the whole activity. Moreover, students and teachers highlighted the agile, dynamic and engaging collaboration achieved using the system when compared to their previous experiences (S7-15, T5). The timing reported in Table 2 also shows the agile enactment of the activity. 
Table 3. Findings: Facilitating flexible orchestration in the classroom

\begin{tabular}{|c|c|}
\hline Findings & $\begin{array}{c}\text { Supporting data } \\
\text { (S, comments of students; } \mathrm{T}, \text { comments of teachers; } \\
\mathrm{O}, \text { observations by researchers })\end{array}$ \\
\hline $\begin{array}{l}\text { The collaborative learning } \\
\text { flow was followed as desired } \\
\text { according to the Jigsaw } \\
\text { intrinsic constraints (every } \\
\text { expert group had more than } 2 \\
\text { members, and every Jigsaw } \\
\text { group included at least a } \\
\text { member expert in each case). } \\
\text { The Orchestration Signal } \\
\text { system was not indispensable } \\
\text { to achieve the orchestration, } \\
\text { however, it decreased the } \\
\text { teachers' workload and } \\
\text { required attention to the } \\
\text { orchestration of students when } \\
\text { distributing the cases and } \\
\text { forming the groups. }\end{array}$ & $\begin{array}{l}\text { - The constraints of the Jigsaw collaborative learning flow were respected, and the } \\
\text { flow of activities and distribution of groups in the classroom were achieved as } \\
\text { desired (see Table 2) } \\
\text { - } \mathbf{4 6 \%} \text { of the students rated the PS-devices as quite useful, } \mathbf{3 8 \%} \text { as very useful, } \\
\mathbf{1 2 \%} \text { as somehow useful, } \mathbf{4 \%} \text { as not useful } \\
\text { - Decrease the teachers' workload } \\
\text { "The system may enable to create different dynamics without the need that the } \\
\text { teacher is close to you explaining the next step to follow..." (S1) } \\
\text { "It avoids that the teacher decide the compositions of the groups... If a student is } \\
\text { not happy in her group, she could not blame the teacher..." (S2) } \\
\text { "I didn't need to indicate students in every moment what case each of them should } \\
\text { read. Students were autonomous identifying their groups and task to accomplish. } \\
\text { The group distribution was easier and agile since I didn't need to pay attention to } \\
\text { where each student were going...." (T1) } \\
\text { "I can pay more attention to the tasks themselves and not that much to the } \\
\text { organization" (T2) } \\
\text { - Limited help of the teacher in the orchestration tasks (explaining meaning of the } \\
\text { signals, tasks descriptions and moving the "signals" for the classroom } \\
\text { collaboration areas) } \\
\text { "Teachers needed to explain how to interpret the signals in the devices" (S3) } \\
\text { "The teacher changes the position of the color cardboards to indicate the new } \\
\text { group working areas" (O1) } \\
\text { "The teacher shout that the Expert phase finished ..." (O2) } \\
\text { - The system is not indispensable } \\
\text { "The device is not indispensable" (S4) } \\
\text { "This can be also done with papers of different colors, though with children using } \\
\text { the devices may be funny" (S5) } \\
\text { "It's helpful but it also depends on how expensive the devices are..." (S6) } \\
\text { "The teacher explains the activity at the beginning but the students ask her to } \\
\text { remind them every task along the phases of the Jigsaw" (O3) }\end{array}$ \\
\hline $\begin{array}{l}\text { Despite the unexpected } \\
\text { incidents, teachers could easily } \\
\text { rearrange the configuration of } \\
\text { the orchestration transparently } \\
\text { to the students. Teachers } \\
\text { largely appreciated the } \\
\text { flexibility supported by the } \\
\text { system. }\end{array}$ & $\begin{array}{l}\text {-The Jigsaw flow was followed meaningfully despite the incidents without } \\
\text { spending extra time (see Table 2). } \\
\text { - Teachers' comments and observations regarding flexibility aspects included: } \\
\text { "The process for sending signals was easy; there was even a student that left the } \\
\text { class during the second phase, and it didn't occasion a problem..." (T3) } \\
\text { "The system is very helpful, because it allows me to make changes during the } \\
\text { activity in the signals to send..." (T4) } \\
\text { "In one of the devices }\left(n^{\circ} 24\right) \text { the red led is not working" (O4) } \\
\text { "One of the students left in the minute } 30 \text { of the activity"(O5) }\end{array}$ \\
\hline $\begin{array}{l}\text { When compared to previous } \\
\text { experiences of students and } \\
\text { teachers, the system showed to } \\
\text { facilitate a more organized and } \\
\text { dynamic collaboration and a } \\
\text { more engaging experience. }\end{array}$ & $\begin{array}{l}\text {-77\% of the students experienced similar collaboration situations in the past } \\
\text { - Collaboration more organized and dynamic: } \\
\text { "The devices speed up the dynamic" (S7) } \\
\text { "The devices facilitated the organization of the activities" (S8) } \\
\text { "Very helpful using the devices because they enables a complete organization" } \\
\text { (S9) } \\
\text { "It appeared to be a very well organized activity!"(S10) } \\
\text { "I value that along the whole activity we keep the rhythm of the dynamic" (S11) } \\
\text { "The system supported the group formation and the changes of groups were more } \\
\text { rapid than previous years..." (T5) } \\
\text { - The system facilitates the movement and mixture of students: } \\
\text { "It's good that not always the groups are formed by the same people" (S12) } \\
\text { "The movement in the classroom is motivating and favors collaboration and } \\
\text { motivation" (S13) } \\
\text { - More engaging: } \\
\text { "The devices open our interest and raise expectations of what will be the next } \\
\text { signal" (S14) } \\
\text { "It's funny to see your color and then look for the place you need to go..." (S15) }\end{array}$ \\
\hline
\end{tabular}


The personal signals were seen and understood fairly well (see Table 4). Though it was not critical for the experience, it is interesting to note that they could see the signals of their classmates (though not as clear as theirs). Depending on the position of the students in the classroom, the cardboards indicating working spaces in the classroom were seen better or worse. Teachers' comments and observations pointed out that the students get familiar to the signals and devices very quickly and the process followed to distribute the signals is easy and agile (T6-7, O6-8).

Table 4. Findings: Usability of the system and directions for improvement

\begin{tabular}{|c|c|}
\hline Findings & Supporting data \\
\hline $\begin{array}{l}\text { Globally, the signals were } \\
\text { seen and understood fairly } \\
\text { well and quickly. }\end{array}$ & $\begin{array}{l}\text { - Signals: } \\
\mathbf{3 8 \%} \text { of the students said that they could see their signals in the PS-devices quite well, } \\
\mathbf{3 5 \%} \text { very well, } \mathbf{1 2 \%} \text { not very well, } \mathbf{0} \% \text { bad } \\
\mathbf{6 2 \%} \text { of the students said that they could see the signals of their classmates quite well, } \\
\mathbf{1 5 \%} \text { very well, } \mathbf{2 3} \% \text { not very well, } \mathbf{0} \% \text { bad } \\
\mathbf{3 5 \%} \text { of the students said that they could see the "cardboard furniture signals" quite } \\
\text { well, } \mathbf{4 2} \% \text { very well, } \mathbf{1 9 \%} \text { not very well, } \mathbf{4} \% \text { bad } \\
\text { - Observations and comments regarding the global usability were: } \\
\text { "The process followed for sending signals was easy" (T6) } \\
\text { "The students get familiar with the device very quickly because it is very easy to use" } \\
\text { (T7) } \\
\text { "Students identify very quickly their colors" (O6) } \\
\text { "All of the students saw the signals almost at the same time" (O7) } \\
\text { "In the third phase students appeared to be used to the devices and understood very } \\
\text { quickly what to do..." (O8) }\end{array}$ \\
\hline $\begin{array}{l}\text { More than a } 70 \% \text { of the } \\
\text { students said that if they } \\
\text { were to organize a similar } \\
\text { activity, they would like to } \\
\text { use the Orchestration Signal } \\
\text { system. When asked about } \\
\text { the positive aspects of the } \\
\text { system they talked about } \\
\text { dynamism, visual indicators, } \\
\text { and engagement. }\end{array}$ & $\begin{array}{l}\text { - 73\% of the participants said that if they were to organize a similar activity, they } \\
\text { would like to use the signal system, } \mathbf{8 \%} \text { said that they won't like to use it and } \mathbf{5 \%} \\
\text { indicates that it would depends on the situation. } \\
\text { - More positive aspects indicated by the students (dynamism, visual, engaging) } \\
\text { "Enabling a more dynamic class" (S16) } \\
\text { "Facilitating a rapid group formation" (S17) } \\
\text { "Fluid organization" (S18) } \\
\text { "Fosters students mobility in the classroom" (S19) } \\
\text { "New, motivating, funny..." (S20) } \\
\text { "Raise expectations, curiosity, engagement..." (S21) } \\
\text { "The organization of the dynamic is highly visible... you do not need to read } \\
\text { continuously the description of the "logistics"..." (S22) } \\
\text { "All the students pay a lot of attention to the device, expecting the signals" (O9) }\end{array}$ \\
\hline $\begin{array}{l}\text { Since the devices were } \\
\text { prototypes, their design was } \\
\text { not optimal in terms of size, } \\
\text { weight and robustness. Some } \\
\text { of the students did not were } \\
\text { the PS-devices as expected } \\
\text { and the students receiving } \\
\text { only one color were } \\
\text { confused thinking that they } \\
\text { might need to see a second } \\
\text { color. Future work proposed } \\
\text { by the teachers include, the } \\
\text { addition of intelligent } \\
\text { functionalities to the PS- } \\
\text { manager, being able to send } \\
\text { signals also to furniture or } \\
\text { locations in the classroom, } \\
\text { and enabling students to } \\
\text { send signals to the teacher } \\
\text { from their PS-devices. }\end{array}$ & 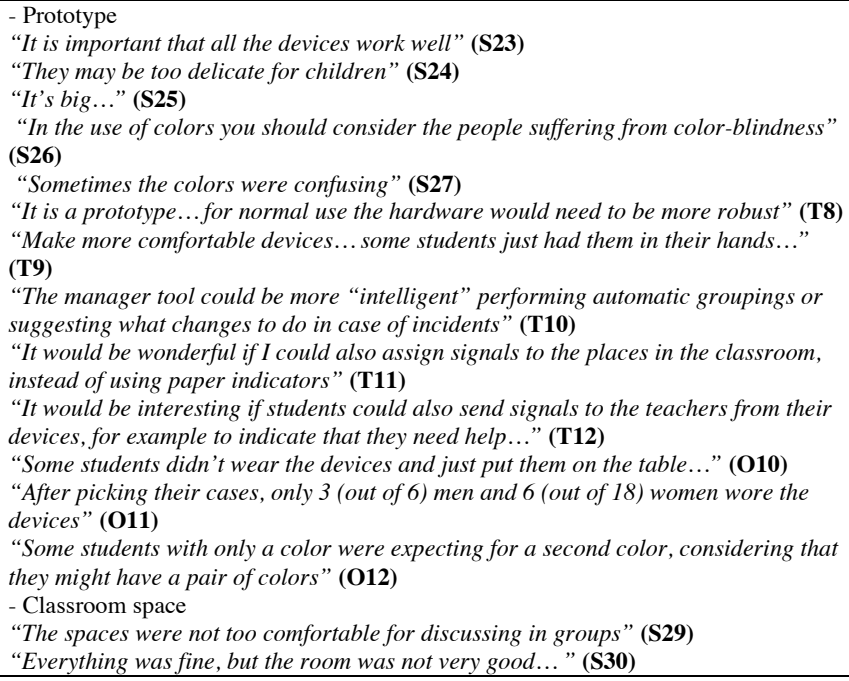 \\
\hline
\end{tabular}


A $73 \%$ of the students said that if they were to organize a similar activity, they would like to use the Orchestration Signal system. They highlighted the dynamism (S16-19), visual indicators (S22), and engagement effect (S20-21, O9) of the approach as its more positive aspects. Regarding the aspects for improvement, it became clear that the robustness, size and weight of the PS-devices are important characteristics that need to be improved towards a lighter, more compact device (S23$25, \mathrm{~T} 8-9, \mathrm{O} 10-11)$. No communication problems in the transmission of the signals appeared during the experience. Finally, the use of mono- and bi-color signals seemed to be confusing, since some students receiving a mono-color signal were waiting during a brief moment for an eventual second color (S26-27, O12). Additional facilities proposed by the teachers to be supported by the system were the incorporation of intelligent functionalities to the PS-manager (T10), being able to send signals also to furniture or locations in the classroom (T11), and enabling students to send signals to the teacher from their PS-devices (T12).

\section{Conclusions and future work}

This paper has introduced a system that uses network linked ubiquitous computing devices to distribute signals to students indicating orchestration aspects in face-to-face settings. Examples of orchestration aspects that can be indicated with the signals include coordination indicators regarding group membership, collaboration areas assigned to each group, or distribution of resources and roles within groups. The prototype is named Orchestration Signal system and includes two components: an Orchestration Signal manager, which enables teachers to configure color signals to be transmitted, and a set of Personal Signal devices, which can be worn by students and display the transmitted orchestration signals.

The Orchestration Signal system has been used in a real classroom activity based on the Jigsaw collaborative learning flow pattern. Students received signals in their personal devices indicating which documents they should read, in which group they were and in which area of the classroom they were expected to collaborate. The findings, analyzed following a mixed evaluation method, show that the system enabled and facilitated the Jigsaw activity with a positive impact in decreasing the teachers' workload regarding the orchestration tasks. When compared to previous similar experiences, participants also indicated that the system supported a more dynamic, agile, organized and engaging activity. The system proved to flexibly support changes derived from unexpected incidents that emerged during the experience.

Future work include conducting new experiences in classrooms and other educational spaces, such as the playground, implementing diverse collaborative learning flow patterns, such as the Pyramid or the Simulation or Roleplay [19]. These new experiences will incorporate revised versions of the prototype towards lighter and 
more compact PS-devices and an easier-to-use OS-manager extended with additional facilities for random composition of groups, consideration of the intrinsic constraints of the flow patterns, etc. Moreover, we plan to incorporate a sound signal to indicate the change of phases and add a new component to the system that will be easily bound to classroom furniture so that it can also receive and visualize configurable signals. Furthermore, we are also working towards supporting active interaction between the personal devices and the manager and between several personal devices, in a mesh node interacting on a multipoint fashion, so as to facilitate collaborative learning activities where the management of the orchestration could be also controlled by the students.

Acknowledgments. This work has been partially funded by the Learn 3 project, (TIN2008-05163/TSI). The authors would also especially like to thank Mar PérezSanagustín, Patricia Santos and other members of the GTI research group for their support and ideas.

\section{References}

1. Ciolfi, L.: Understanding spaces as places: extending interaction design paradigms. Cognition, Technology \& Work 6(1), 37--40 (2004)

2. Gee, J.P.: Semiotic social spaces and affinity spaces: from The Age of Mythology to today's schools. In: Barton, D., Tusting, K. (eds.), Beyond Communities of Practice: Language, Power and Social Context, pp. 214--232, Cambridge University Press, Cambridge (2005)

3. Oblinger, D.: Leading the transition from classrooms to learning spaces. EDUCAUSE, Quaterly 28(1) 14--18 (2005)

4. Suthers, D.: Technology affordances for intersubjective learning: A thematic agenda for CSCL. In: 2005 conference on Computer support for collaborative learning, pp. 662--671. Taipei, China (2005)

5. Dillenbourg, P., Huang, J., Cherubini, M.: Interactive Artifacts and Furniture Supporting Collaborative Work and Learning. Springer Science, New York (2009)

6. Kirschner, P.: Can we support CSCL? Educational, social and technological affordances for learning. In: Kirschner, P. (ed.) Three worlds of CSCL: Can we support CSCL? pp. 7-47, Heerlen, The Netherlands (2002)

7. Huang, J., Cherubini, M., Nova, N., Dillenbourg, P.: Why would furniture be relevant for collaborative learning?. In Dillenbourg et al. (eds.) Interactive Artifacts and Furniture Supporting Collaborative Work and Learning, pp. 1--13, Springer, NY, USA (2009)

8. Arroyo, E., Ardaiz, O., Righi, V., Blat, J.: Distributed multi-touch virtual collaborative environments. In: 2010 International Symposium on Collaborative Technologies and Systems, pp. 635--636. Illinois, USA (2010)

9. Bachour K., Kaplan F., Dillenbourg P.: An interactive table for supporting participation balance in face-to-face collaborative learning. IEEE Transactions on Learning Technologies 3(3), 203--213 (2010)

10. Kemp, R., Kemp, E., Mohanarajah, T.: Supporting group learning using a digital whiteboard. Computer Human Interaction 3101, 594--598 (2004) 
11. Jermann, P., Zufferey, G. Dillenbourg, P.: Tinkering or Sketching: Apprentices' Use of Tangibles and Drawings to Solve Design Problems. In: $3^{\text {rd }}$ European Conference on Technology Enhanced Learning, pp. 167-178, Maastricht, The Netherlands (2008)

12. Bachour, K., Alavi, H. S., Kaplan, F., Dillenbourg, P. Low-resolution ambient awareness tools for educational support. In: CHI 2010 Workshop: Next Generation of HCI and Education, Atlanta, GA (2010)

13. Dix, A., Rodden, T., Davies, N., Trevor, J., Friday, A. Palfreyman, K.: Exploiting space and location as a design framework for interactive mobile systems. ACM Transactions on Computer-Human Interaction, 7(3), 285-321 (2000)

14. Roschelle, J., Pea, R.: A walk on the WILD side: How wireless handhelds may change computer-supported collaborative learning. International Journal of Cognition and Technology, 1(2), 145-168 (2002)

15. Pérez-Sanagustín, M., Ramírez-González, G., Hernández-Leo, D., Muñoz-Organiero, M., Santos, P., Blat, J., Delgado-Kloos, C.: Discovering the campus together: a mobile and computer-based learning experience, Journal of Network and Computer Applications (in press, http://dx.doi.org/10.1016/j.jnca.2011.02.011)

16. Santos, P., Pérez-Sanagustín, M., Hernández-Leo, D., Blat, J.: QuesTInSitu: from tests to routes for assessment in situ activities (submitted)

17. Dillenbourg, P., Järvelä, S., Fischer, F.: The evolution of research on computer-supported collaborative learning. In: Balacheff, N., Ludvigsen, S., Jong, T., Lazonder, A., Barnes, S. (eds.), Technology-enhanced learning, pp. 3-19, Springer Netherlands (2009)

18. Hernández-Leo, D., Villasclaras-Fernández, E.D., Jorrín-Abellán, I.M., Asensio-Pérez, J.I., Dimitriadis, Y., Ruiz-Requies, I., Rubia-Avi, B.: Collage, a Collaborative Learning Design Editor Based on Patterns. Educational Technology \& Society 9(1), 58--71 (2006)

19. Hernández, D., Asensio, J.I., Dimitriadis, Y., Villasclaras, E.D.: Pattern languages for generating CSCL scripts: from a conceptual model to the design of a real situation. In: Goodyear P., Retalis, S. (eds.). E-learning, design patterns and pattern languages, pp. 4964, Sense Publishers (2010)

20. JeeNode low-cost combination of radio and microcontroller board, http://jeelabs.net/projects/hardware/wiki/JeeNode

21. Creswell, J.W.: Research design : qualitative, quantitative, and mixed method approaches / John W. Creswell. Sage Publications, Thousand Oaks (2009)

22. Guba, E.G.: Criteria for assessing the trustworthiness of naturalistic inquiries. Educational Communication and Technology: A Journal of Theory, Research, and Development 29(2), 75-91 (1981) 